\title{
Public health for paediatricians: engaging young people from marginalised groups
}

\author{
Emma Rigby, Lindsay Starbuck
}

- Additional material is published online only. To view please visit the journal online (http://dx.doi.org/10.1136/ archdischild-2016-312065).

Association for Young People's Health, Association for Young People's Health, London, UK

\section{Correspondence to}

Emma Rigby, Association for Young People's Health, 32-36 Loman Street, London SE1 OEH, UK; emma@ youngpeopleshealth.org.uk

Received 22 November 2016 Accepted 23 June 2017 Published Online First 10 August 2017

\section{Check for updates}

To cite: Rigby E, Starbuck L. Arch Dis Child Educ Pract Ed 2018:103:207-210.

\begin{abstract}
Young people from marginalised groups can be excluded from health services because of reduced access, increased stigma and health inequalities. In addition, the stress associated with discrimination and stigma can have serious effects on individual health. This article explores how stigma affects young people's access to services and how health professionals can improve their practice and support for marginalised young people to achieve the best possible health outcomes. A better understanding of local populations of young people and their needs is key to improving services and support. Working in partnership with voluntary and community sector organisations is also important. In addition, improvements can be made by promoting better communication with young people and providing extra support to help them follow treatment plans.
\end{abstract}

\section{INTRODUCTION}

The UN Convention on the Rights of the Child $1989{ }^{1}$ ratified by the UK, entails a commitment by all professionals working with children and young people to promote and defend their rights. Article 24 states that 'every child has the right to the best possible health'. What does this Convention and the resulting rights mean for groups of young people who face barriers to seeking help? How can health professionals provide the best possible care to young people who are not coming through their doors?

This article explores some of the reasons why marginalised young peopleaged 10-24-have said they do not seek help as well as providing suggestions for improving their health outcomes. It is based on surveys and research conducted with marginalised young people as well as research projects led by young people. By marginalised, we mean young people who face reduced access to services, increased stigma and health inequalities. We use 'marginalised' in recognition of the social determinants of health inequalities that disadvantage entire groups as opposed to 'vulnerable', which often focuses on health outcomes at an individual level.

\section{WHO IS MARGINALISED?}

Any young person can be marginalised based on their circumstances and experiences. This includes but is not exclusive to homeless young people, young people living in deprivation, young offenders, young carers, lookedafter young people, young people with special educational needs and disabilities, lesbian, gay, bisexual, transgender, queer and intersex young people, Black and Minority Ethnic (BAME) young people and those who have been affected by abuse and exploitation.

The Association for Young People's Health (AYPH) produced an infographic $^{2}$ (online Supplementary file 1 supplementary file 1) on marginalised groups of young people and the challenges they face when accessing services. It highlights significant numbers of young people facing stigma and the resulting barriers to getting the help they need. This includes 83000 homeless young people ${ }^{3}$ in the UK and an estimated 70000 young carers. As one young carer states,

'I quite often go in with my mother when she goes to the doctor, but they still don't recognise the fact that I'm a young carer and still don't pay attention or give time to that matter.'

The health needs of significant populations of young people can be missed when professionals focus narrowly on individual physical health.

A lack of preventive care and emotional support for young people facing hardship can have a significant impact on life 
Box 1 What stops young people from getting help or advice on health issues?

$60 \%$ Feeling judged

- $51 \%$ Embarrassment

- $44 \%$ Being let down by services in the past

> $42 \%$ Fear

- $31 \%$ Location/opening times

- $22 \%$ Concerns about confidentiality

Association for Young People's Health Young People's

Feedback on Health Issues. 2014 London: AYPH.

Responses from 51 young people.

chances. Up to $41 \%$ of young offenders suffered a childhood bereavement and $48 \%$ of transgender young people have attempted suicide. ${ }^{4}$ Where prevention and support services do exist, there is a danger that they are not reaching young people who need them most.

\section{WHY DON'T MARGINALISED YOUNG PEOPLE SEEK HELP?}

Young people from marginalised groups often do not seek help because they are worried that the staff will judge them or not believe them. According to Weiss et $a l,{ }^{5}$ stigma is a social process where adverse social judgement is directed at specific medical conditions (ie, HIV/AIDS) or at specific groups for characteristics unrelated to health (ie, race, ethnicity and sexual orientation); both of which can negatively affect health outcomes and take up of services ${ }^{5}$.

Young Minds conducted a survey in $2010^{6}$ of 2629 young people aged 9-25 and found that young people with mental health issues had a series of concerns related to stigma. "Some young people have reported that they had been put off seeking help from people outside of the family because they see adults as: overly controlling, dismissive of children and young people's accounts of their emotional problems, blaming and over-keen to medicate." 7

AYPH conducted a survey to find out young people's views on health and well-being (box 1). Concerns about stigma were rated highest while confidentiality was lowest, indicating that how they will be perceived and treated by professionals is a bigger barrier than that of being judged by others for using services. This is significant as confidentiality has been cited in the past as young people's primary concern. Respondents also shared a fear of being turned away or not being believed by professionals.

Young people's fears and the stigma they face are major factors that contribute to how and if they will engage with health professionals. Simply offering universal services will not lead to health equality with so many young people facing barriers long before they set foot in a clinic, hospital or General Practitioner surgery.

\section{WHAT HAPPENS WHEN MARGINALISED YOUNG} PEOPLE DO NOT GET HELP?

The stress associated with discrimination and stigma can have serious effects on individual health. There is a body of stigma literature, looking at the issue from a sociological perspective in order to assess the negative health impacts stigma has on entire populations. Social isolation, psychological and behavioural disruption and stress as responses to social stigma can all lead to long-term health consequences if left unchecked. ${ }^{8}$ Stress can also lead to harmful coping behaviours ${ }^{9}$ and negative self-regard. ${ }^{10}$ It is therefore imperative that those working with young people do all they can to address and break down stigma as part of any preventive care strategy.

Unfortunately, young people are often unable to access preventive or specialist care, sometimes failing to meet thresholds for services like Child and Adolescent Mental Health Services. As one young person puts it,

'there's no help available until the problem has become totally unmanageable. ${ }^{, 11}$

Preventing problems from becoming unmanageable is essential to support young people to claim their right to the best possible health and to enable them to develop into adults who face fewer health inequalities. Although societal stigma plays an important part in determining access in the first place, there is still much health providers can be doing to meet the needs of marginalised young people.

\section{UNDERSTANDING LOCAL POPULATIONS OF YOUNG PEOPLE}

A better understanding of local populations of young people and their needs is key to improving services and supporting them. Those delivering and planning local services need to understand the issues facing young people in their area to increase access to services. Some areas have a particularly young population, high levels of diabetes and/or obesity, a significant university population, etc. In other areas, the issues will be different with perhaps small numbers of young people who have a broad range of needs and challenges. Understanding young people in your area is key to ensure that young people's needs do not get deprioritised just because they represent a smaller proportion of the local population. ${ }^{12}$

Working in partnership with voluntary and community sector organisations can make it easier for marginalised groups to use health services. ${ }^{13}$ Partnering with a youth advice service and offering sessions to marginalised young people can provide vital care to young people who may struggle to access traditional services. The GP Champions for Youth Health project (box 2) used this approach and identified particular barriers for young people with no fixed address. Lack of income to travel to services is 


\section{Box 2 GP Champions for Youth Health}

The GP Champs project trialled a new approach with 10 GP practices across England working in partnership with a local Youth Information Advice and Counselling service. The work highlighted some interesting models and the potential to improve referrals. However, most significantly, it showed that by working together, the organisations built a level of trust and cooperation which would be useful beyond the life of the project to support young people's health and wellbeing.

'Working with the voluntary sector forces me to approach situations from a different angle and not over medicalise issues.' General Practitionner Association for Young People's Health, GP Champions for Youth Health: Toolkit for General Practice. 2015. London: AYPH.

also a barrier for many young people particularly in rural and isolated areas.

\section{How can health professionals support more marginalised young people?}

The right of every young person to have the best possible health is contingent on services actively working to level the field. This means taking into account the kinds of stigma and health inequalities marginalised young people face. It also requires thinking critically about how health practices may reinforce stigma. It must involve moving from a one-size-fits-all consultation to one that takes into account the causes of health inequalities.

When a health service is difficult to physically access, only the most well-resourced and able-bodied young people will be able to use it. Fear, stigma and previous negative experiences can also impact how and if young people will use services. When marginalised young people overcome barriers and make it to the consulting room, it is crucial that professionals provide a service that recognises their social circumstances and how their current and future health is affected by them. ${ }^{14}$

\section{Improving everyday practice}

Understanding what is going on for the young person

Talking to young people about their health holistically is central to better understanding and responding to their needs. The HEEADSSS guidelines which provide a framework for considering all aspects of a young person's life are a good starting point (box 3). A HEEADSSS psychosocial assessment provides a baseline to establish whether or not the young person is facing difficulties that may impact their health.

It's important to ensure that young people have time to talk about their concerns and have all their questions answered. Making sure professionals have time on their own with the young person without parents and/or carers present is also key. Guidance on confidentiality, ${ }^{15}$ such as Gillick and Fraser ${ }^{16}$ competence is important to have at hand. Disclosures often come at the end of a consultation but they will not be made
Box 3 HEEADSSS framework for a psychosocial interview with young people ${ }^{21}$

- Home environment-where does the young person live and who with? Do they have good support systems at home?

- Education and employment-at what stage of education/employment are the young people at? Are there any changes they are expecting soon?

- Eating - does their weight concern them? Have they been on a diet in the last year?

- Activities-what do they like doing in their leisure time? Do they have a supportive peer group?

- Drugs - does the young person smoke, drink or use drugs?

- Sexuality—relationships, sex and sexuality.

- Suicide/depression - mental health and well-being.

Safety - personal safety, injury, online safety.

at all if the young person feels rushed or not listened to. Sometimes a second consultation will be needed to provide extra time and an opportunity to increase trust. This should be organised with the young person before they leave so they do not have to re-negotiate access to the service.

Establishing connections between personal circumstances and health is key both in one to one consultations and team meetings. For example, if a young person has housing problems their physical health may be affected by cold, damp or mould but it could also be a source of stress and anxiety. ${ }^{17}$

Knowing about local services and other sources of support

Find out about local services that can help young people with other issues (box 4). You might know how to treat anxiety around insecure housing but young people may need a professional who can advise them on their rights when facing eviction. Signpost young people to someone who has the skills to meet their needs. Dealing with the underlying causes of emotional and physical health problems is central to resolving issues and moving forward. As local social care provision can change frequently, this could be a role for public health. ${ }^{18}$

Supporting young people to follow treatment

Explaining treatment options clearly and making sure young people fully understand them is paramount. It is easy for someone to forget details once they leave the room. Providing a printed document with all the information, including contact details for local specialist services, is really helpful.

Ask young people directly if they will have any trouble following treatment. This could be due to the lack of money to access prescriptions or a young carers' responsibilities that make attending appointments difficult. There could be a reluctance to follow treatment advice because of substance misuse issues or eating disorders. Such issues 


\section{Box 4 Local services to have contact with}

- Young Carer's project

- Lesbian, gay, bisexual, transgender, queer and intersex project or service

- Young people's mental health service

- Housing, benefits and debt advice services

- Young people's sexual health or GUM clinic

- Specialist CSE (Child Sexual Exploitation) service

- Childhood Bereavement service

You can find out more about local services through your local authority or local council for voluntary services. National organisations can also provide details of local organisations.

can be surfaced through a HEEADSSS interview but it is worth explicitly discussing them in the context of following treatment.

Think about any options you could offer to communicate with young people besides face-to-face consultations in medical settings. Could you follow-up with a phone call or a Skype chat? ${ }^{19}$ Ask young people what would work for them and see if you can accommodate. There are some very good examples of Apps and other tools which can support young people to manage longterm conditions or get health information but they will not be useful for all young people depending on their needs and access to technology. ${ }^{20}$

\section{CONCLUSION}

There are significant and varied populations of marginalised young people across the UK. Finding ways in everyday practice and as part of service development to provide more accessible services is essential to support young people's health and work to reduce health inequalities. There are practical ways to do this in consultations and service planning. This may include altering your health offer and/or promoting it in different ways to particular groups. Building relationships with other local services is also key. If some young people never come through the door to seek help because of fear, discrimination and stigma, there is no way they will get support to claim their right to the best possible health.

\section{Competing interests None declared.}

Provenance and peer review Commissioned; externally peer reviewed.

(C) Article author(s) (or their employer(s) unless otherwise stated in the text of the article) 2018. All rights reserved. No commercial use is permitted unless otherwise expressly granted.

\section{REFERENCES}

1 Nations U. United National Convention on the rights of the child (UNCRC). Geneva: United Nations, 1989.

2 Association for Young People's Health. Reaching marginalised young people, 2016. http://www.youngpeopleshealth.org.uk/ reaching-marginalised-young-people.
3 Clark A, Burgess G, Morris S. Estimatingestimating the Scale of Youth Homelessness in the UK. Cambridge: Cambridge Centre for Housing and Planning Research, 2015.

4 Nodin N, Elizabeth P, Tyler A, et al. The RaRE Research Report: lgbot Mental Health - Risk and Resilience Explored. Project Report. London: PACE (Project for Advocacy Counselling and Education), 2015.

5 Weiss MG, Ramakrishna J, Somma D. Health-related stigma: rethinking concepts and interventions. Psychol Health Med 2006;11:277-877.

6 Young Minds. See beyond our labels: Young Minds briefing on young people's views about mental health. London: Young Minds, 2010a.

7 Young Minds. Young minds Stigma: A Review of the Evidence. London: Young Minds, 2010.

8 Hatzenbuehler ML, Phelan JC, Link BG. Stigma as a fundamental cause of population health inequalities. Am J Public Health 2013;103:813-21.

9 Williams DR, Neighbors HW, Jackson JS. Racial/ethnic discrimination and health: findings from community studies. Am J Public Health 2008;98(Suppl 9):S29-37.

10 Meyer IH. Prejudice, social stress, and mental health in lesbian, gay, and bisexual populations: conceptual issues and research evidence. Psychol Bull 2003;129:674-97.

11 Association for Young People's Health. Young People's Feedback on Health Issues. London: AYPH, 2014.

12 Association for Young People's Health. A public health approach to promoting young people's resilience. London: AYPH, 2016.

13 Department of Health, PHE, NHS England. Review of partnerships and investment in voluntary and community and social enterprise organisations in the health and care sectorfinal report. London: Department of Health, 2016.

14 Department of Health. Future in Mind: chapter 6 Care for the most vulnerable. London: Department of Health, 2015.

15 Royal College of General Practitioners. Confidentiality and Young Personperson's Toolkit. London: Royal College of General Practitioners, 2016.

16 NSPCC. A child's legal right Gillick competency and Fraser guidelines. London: NSPCC. https://www.nspcc.org.uk/ preventing-abuse/child-protection-system/legal-definitionchild-rights-law/gillick-competency-fraser-guidelines/ (accessed 9 Nov 2016).

17 Shelter. Chance of a lifetime: the impact of bad housing on children's lives. London: Shelter, 2006.

18 New Philanthropy Capital. Supporting good health: the role of the charity sector. London: NPC, 2014.

19 Greenhalgh T, Vijayaraghavan S, Wherton J, et al. Virtual online consultations: advantages and limitations (VOCAL) study. BMJ Open 2016;6:e009388.

20 Powell J, Martin S, Sutcliffe P, et al. Young people and mental health: the role of information and Communications Technology. Warwick University Medical School: Warwick, 2010.

21 Klien DA, Goldenring JM, Adleman WP. HEEADSSS 3.0 "The psychosocial interview for adolescents updatedfor a new century fuelled by media. Contemporary paediatrics 2014:1-16. Available at: http://contemporarypediatrics. modernmedicine.com/contemporarypediatrics/news/probingscars-how-ask-essentialquestions? page $=$ full $($ accessed $9 \mathrm{Nov}$ 2016). 